\title{
Principais dificuldades dos catadores de lixo de Petrolina, PE, e Juazeiro, BA
}

\author{
Main difficulties of garbage collectors at Petrolina, PE, and Juazeiro, BA
}

\author{
Raissa Rachel Salustriano da Silva ${ }^{[a]}$, Paloma Clementino da Cruz Lubarino ${ }^{[\mathrm{b}]}$, \\ Geisa Mayana Miranda de Souza ${ }^{[c]}$
}

\footnotetext{
[a] Bióloga, Pós-Graduanda em Gestão Ambiental, Mestranda da Universidade Federal do Piauí (UFPI), Petrolina, PE - Brasil, e-mail: raissasalustriano@yahoo.com.br

[b] Bióloga, Pós-Graduanda em Gestão Ambiental das Faculdades Montenegro, Petrolina, PE - Brasil, e-mail: paloma.ccl@hotmail.com

[c] Graduanda do curso de Ciências Biológicas pela Universidade do Estado de Pernambuco (UPE), bolsista da Embrapa Semiárido, Petrolina, PE - Brasil, email: geisamayana@yahoo.com.br
}

\begin{abstract}
Resumo
O rejeito (lixo) é um conjunto heterogêneo de elementos desprezados que assumem um caráter depreciativo e que gera inúmeros problemas ambientais; por isso, ele suscita muitos debates. Dentre eles estão os aspectos sociais de pessoas que utilizam a coleta do lixo como forma de driblar a exclusão socioeconômica (escassez de oportunidades de inserção profissional). Essa coleta para reciclagem acontece principalmente pela ação de catadores de lixo, vinculados ou não a uma associação. Esses profissionais necessitam de pesquisas que os ajudem no exercício das suas atividades e que alertem a sociedade quanto às melhores formas de participar desse trabalho tão importante. Nesse sentido, este trabalho visou a fazer uma caracterização socioeconômica dos catadores de lixo das cidades de Petrolina, PE, e de Juazeiro, BA, listar os principais problemas encontrados no cotidiano e detectar qual destes é o mais crítico. Constatou-se que a maioria é do sexo feminino, possui baixa escolaridade, coleta vários tipos de materiais que pesam entre 200 e $300 \mathrm{~kg}$, obtendo com eles cerca de $\mathrm{R} \$ 200$. Os principais problemas apontados foram a insuficiência da remuneração recebida, os problemas de saúde adquiridos durante as coletas e as violências sofridas. A baixa remuneração foi destacada como o mais crítico.
\end{abstract}

Palavras-chave: Lixo. Reciclagem. Catadores. Caracterização socioeconômica. 


\begin{abstract}
The waste (garbage) is a heterogeneous set of despised elements which assume a derogatory character and generate many environmental problems; that's why it raises many debates. Among them are the social aspects of people that use garbage collection as a way to circumvent the socio-economic exclusion (lack of opportunities for employability). This collection for recycling occurs primarily by the action of scavengers, linked or not to an association. These professionals need research to help them in carrying out their activities and to alert society about the best ways to participate in this important work. In this sense, this work aimed at making an economic characterization of the garbage collectors of the cities of Petrolina, PE, and Juazeiro, BA, listing the major problems encountered in daily life and identify which of these is most critical. It was found that the majority are female, have low education, collect various types of materials that weigh between 200 and $300 \mathrm{~kg}$, yielding about $R \$ 200$. The main problems mentioned were: the inadequacy of the remuneration received, the health problems acquired during the surveys and the violence suffered. Low pay was highlighted as the most critical problem.
\end{abstract}

Keywords: Trash. Recycling. Garbage. Socioeconomic characterization.

\title{
Introdução
}

O lixo, também conhecido como "rejeito", é tecnicamente chamado de resíduos sólidos urbanos (RSU). Esses resíduos são um conjunto heterogêneo de elementos desprezados durante um dado processo, e pela forma como são tratados, assumem um caráter depreciativo, sendo associados à sujeira, repugnância, pobreza, falta de educação e outras conotações negativas. Partindo dessa premissa, o lixo não pode ser deixado em qualquer lugar. Além dessa questão existem outras mais importantes, que são as concernentes ao ambiente. Nesse âmbito dos problemas ambientais, o lixo é um dos assuntos mais abordados e de difícil resolução, já que é impossível não produzi-lo. Essa preocupação se torna maior especialmente em grandes centros urbanos de países subdesenvolvidos. Segundo Larrea (1999), a geração de RSU é proporcional ao crescimento populacional, suscita uma maior demanda por serviços de coleta pública e esses resíduos, se não coletados e tratados adequadamente, provocam efeitos diretos e indiretos na saúde, além da degradação ambiental.

Em função disto, há muitas discussões a respeito dessa problemática e, como fruto desses debates, existem alguns documentos, tais como o capítulo 21 do documento final produzido na Conferência da Organização das Nações Unidas (ONU) sobre Meio Ambiente e Desenvolvimento (CNUMAD), a Eco-92. Nele, fica evidenciada a preocupação mundial em relação aos problemas ligados aos RSU, estabelecendo a solução destes como um dos principais compromissos da humanidade para as futuras gerações o desenvolvimento sustentável, que deverá conciliar justiça social, eficiência econômica e equilíbrio ambiental (ONU, 1999). Há também as diretrizes da Agenda 21, que seguem as recomendações da CNUMAD e indicam como estratégias para o gerenciamento adequado de RSU: a minimização da produção de resíduos; a maximização de práticas de reutilização e reciclagem ambientalmente corretas; a promoção de sistemas de tratamento e disposição de resíduos compatíveis com a preservação ambiental; a extensão de cobertura dos serviços de coleta e destino final (MMA, 1999).

O aumento na geração de RSU é um problema atual e crescente em diversos países da América Latina, particularmente mais grave em países com maiores demandas e menor oferta de serviços de limpeza pública (ACURIO et al., 1997). Não se sabe ao certo a quantidade de RSU produzida que não é coletada, estimando-se que não são recolhidos de 30\% a 50\% dos resíduos gerados nas cidades dos países em desenvolvimento (OPS, 1993). As pesquisas realizadas por Acurio et al. (1997) apontam uma taxa de geração per capita diária de 0,3 a 0,8 kg/habitantes/dia de resíduos sólidos domiciliares (RSD) e de 0,5 a 1,2 kg/ habitantes/dia de resíduos sólidos municipais (RSM - provenientes da geração residencial, comercial, institucional e de pequena indústria e artesanato), sendo a média regional deste último de $0,92 \mathrm{~kg} / \mathrm{habitantes} /$

Rev. Acad., Ciênc. Agrár. Ambient., Curitiba, v. 8, n. 2, p. 235-248, abr./jun. 2010 
dia. Pesquisas atuais demonstram o aumento dessa geração de lixo por dia, passando agora para 1,0 a 1,2 $\mathrm{kg} /$ habitante/dia, segundo os dados da Pesquisa Nacional por Amostra de Domićlios (PNAD), realizada no Brasil em 1996; a mesma pesquisa aponta que 79,9\% dos domićlios particulares permanentes tinham o lixo coletado (IBGE, 2007).

Entretanto, o acesso à coleta no Brasil apresenta características de desigualdades, conforme a região. Em 2005, o Nordeste apresentava a menor taxa de lixo coletado (59,7\%) e a região Sudeste a maior, com 90,1\% (IBGE, 2007). Porém, assim como a coleta, a destinação desse lixo deve ser estrategicamente pensada. A reciclagem é um sistema de recuperação de recursos projetados para recuperar e reutilizar resíduos, transformando-os novamente em substâncias e materiais úteis à sociedade, que poderíamos denominar de matéria secundária. Outro conceito bastante difundido de reciclagem é que ela é, na sua essência, uma forma de educar e fortalecer nas pessoas o vínculo afetivo com o meio ambiente, despertando o sentimento do poder de cada um para modificar o meio em que vivem (CALDERONI, 1996).

Capucha (1998) concluiu que no Brasil, assim como no mundo inteiro, a sociedade passa por "distanciamento econômico", e nesse tipo de sistema de exclusão muitos acabam enfrentando escassez de oportunidades de inserção profissional, tendo que recorrer a métodos alternativos para sobreviver, como a coleta de materiais. A coleta de materiais recicláveis acontece principalmente pela ação de catadores de lixo, vinculados ou não a uma associação. Esses profissionais necessitam de pesquisas para ajudá-los no exercício das suas atividades, bem como alertar a sociedade quanto à melhor forma de colaborar nesse trabalho, que é imprescindível tanto para os profissionais da coleta quanto para o meio ambiente.

Nesse sentido, este trabalho visa a fazer uma caracterização socioeconômica dos catadores de lixo das cidades de Petrolina, PE, e de Juazeiro, BA, bem como abordar quais são os principais problemas encontrados no cotidiano e detectar entre eles qual é o mais crítico.

\section{Materiais e métodos}

A pesquisa foi realizada a partir da aplicação de um questionário (Figuras 1 e 2), o qual foi divido em duas partes. Na primeira parte as questões visavam à caracterização socioeconômica dos catadores, a partir dos seguintes aspectos: sexo; faixa etária; escolaridade; tempo em que exerce a atividade de coleta de lixo; locais onde realiza a coleta; tipos de materiais vendidos; frequência com que são vendidos; peso do material vendido; valor obtido nesta venda; quantas pessoas vivem dessa renda; se recebem benefícios sociais do governo.

A segunda parte do questionário versava sobre as principais dificuldades encontradas pelos catadores de lixo, e nela constavam as seguintes questões: a remuneração adquirida com a venda dos materiais é suficiente para sustentar sua família?; adquiriu problemas de saúde decorrente dessa atividade?; sofreu alguma violência no exercício da profissão?; já sofreu algum preconceito enquanto coletava?; quantas horas geralmente trabalha por dia?; envolve seu(s) filho(s) ou outra(s) criança(s) menor(es) na coleta?; está associado a alguma cooperativa?; acredita faltar apoio da comunidade e do poder público na coleta seletiva do lixo?; acredita ser importante a implantação de uma coleta seletiva em Petrolina e Juazeiro?; Há consequências da proibição da coleta de materiais no "Raso da Catarina" (lixão localizado na cidade de Petrolina)?; é fácil encontrar pontos de venda?; acha que o preço pago pelos materiais é justo?; dessas temáticas abordadas, qual é a mais crítica?

Os questionários foram aplicados por estudantes do curso de pós-graduação em Gestão Ambiental da Faculdade Monte Negro e as entrevistas realizadas entre os dias 7 e 25 de agosto de 2009. Os 32 catadores entrevistados (18 em Petrolina e $14 \mathrm{em}$ Juazeiro) foram abordados nos locais em que vendem os materiais recicláveis, localizados nos bairros João de Deus, Gercino Coelho, José e Maria, Jardim Amazonas e São Gonçalo, na cidade de Petrolina; e nos bairros Argemiro, Codevasf, Malhada da Areia, Tabuleiro e Itaberaba, na cidade de Juazeiro. Os dados foram tabulados e, a partir da soma das respostas de cada uma das questões abordadas, foi possível estabelecer quantos catadores estavam em cada um dos patamares afixados para múltipla escolha (eles podem ser observados nas tabelas) estabelecidos para cada parâmetro. Por exemplo, para o parâmetro "faixa etária", foram estabelecidos os seguintes patamares: até 20 anos, de 20 a 40 anos e acima de 40 anos. 


\section{Principais dificuldades dos catadores de lixo de Petrolina - PE e Juazeiro - BA}

\section{Parte I - Caracterização socioeconômica dos catadores}
1. Sexo:
( ) Feminino
( ) Masculino

2. Faixa etária:
( ) até 20 anos
( ) de 20 a 40 anos
( ) acima de 40 anos

\section{Escolaridade:}

( ) Ensino Fundamental incompleto

( ) Ensino Fundamental completo

( ) Ensino Médio incompleto

( ) Ensino Médio completo

( ) Apenas alfabetizado

( ) Não foi alfabetizado ou não respondeu

\section{A quanto tempo exerce a} atividade:

( ) Menos de 1 ano
( ) De 3 anos
( ) Mais de 10 anos
( ) Não respondeu

5. Materiais vendidos:

( ) Papel

( ) Papelão

( ) РET

( ) Alumínio

( ) Vidro

( ) Todos os materiais

( ) Não responderam

\section{Onde coleta materiais?}
( ) Supermercados
( ) Hospitais
( ) Escolas
( ) Residências
( ) Outras opções

7. Frequência da venda do material:

( ) Diariamente

( ) Semanalmente

( ) Mensalmente

( ) Não respondeu

( ) Outra opção

8. Peso do material vendido por mês:
( ) Até $50 \mathrm{~kg}$
( ) $50 \mathrm{~kg} \mathrm{a} 100 \mathrm{~kg}$
( ) $100 \mathrm{a} 200 \mathrm{~kg}$
( ) 200 a $300 \mathrm{~kg}$
( ) Mais de $300 \mathrm{~kg}$

9. Valor recebido pelo material vendido por mês:
( ) 10 a 50 reais
( ) 51 a 100 reais
( ) 101 a 200 reais
( ) 201 a 300 reais

\section{Quantas pessoas vivem} dessa renda:

( ) 1 pessoa

( ) 2 pessoas

( ) 3 pessoas

( ) 4 pessoas

( ) 5 pessoas

( ) 6 pessoas

( ) Mais de 6 pessoas

10. Recebem benefícios sociais do governo:
( ) Não recebe
( ) Bolsa escola
( ) Bolsa família
( ) Outro benefício
( ) Não respondeu

\section{Parte II - Principais dificuldades}

1. A remuneração adquirida com a venda dos materiais é suficiente para sustentar sua família?

( ) É mais que o necessário

( ) É o suficiente

( ) É pouco

2. Adquiriu problemas de saúde decorrentes dessa atividade?

( ) $\mathrm{Sim}$

( ) Agravei problemas de saúde já existentes

( ) Não adquiri nenhum problema

3. Sofreu alguma violência no exercício da profissão?

( ) Sim, violência verbal

( ) Sim, violência física

( ) Nunca sofri violência

4. Geralmente trabalha quantas horas por dia?

( ) 6-8 horas por dia

( ) 8-10 horas por dia

( ) Mais de 10 horas por dia

5. Já sofreu algum preconceito enquanto coletava ou por ser conhecido o exercício da coleta?

( ) Sim, algumas vezes

( ) Sim, com frequência

( ) Nunca sofri preconceito

6. Você acaba tendo que envolver seus filhos ou outras crianças menores na coleta?

( ) Sim, mas as crianças continuam indo à escola

( ) Sim, por isso as crianças não vão à escola

( ) Não tenho crianças trabalhando comigo
7. Você está associado a alguma cooperativa?

( ) Sim, o trabalho fica mais lucrativo assim

( ) Sim, mas não obtive benefícios

( ) Não sou associado

8. Falta apoio da comunidade e do poder público na coleta seletiva do lixo?

( ) Falta apoio, mas não faz tanta diferença

( ) Falta apoio, ele seria muito importante

( ) Tenho apoio na comunidade onde coleto

9. O que você acha da proibição de coletar material no Raso da

Catarina?

( ) Tive uma redução na coleta após a proibição

( ) Não tive dificuldade de trabalhar após a proibição

( ) Não coletava material no Raso da Catarina

10. Seria importante a implantação de uma coleta seletiva em

Petrolina?

( ) $\operatorname{Sim}$

( ) Não

11. É fácil encontrar pontos de venda?

( ) $\operatorname{Sim}$

( ) Não

12. Acha que o preço pedido pelos materiais é justo? ( ) $\operatorname{Sim}$

( ) Não

Figura 1 - Questionário aplicado aos catadores de lixo, composto de: parte I - caracterização socioeconômica dos catadores; parte II - principais dificuldades encontradas pelos catadores de lixo 


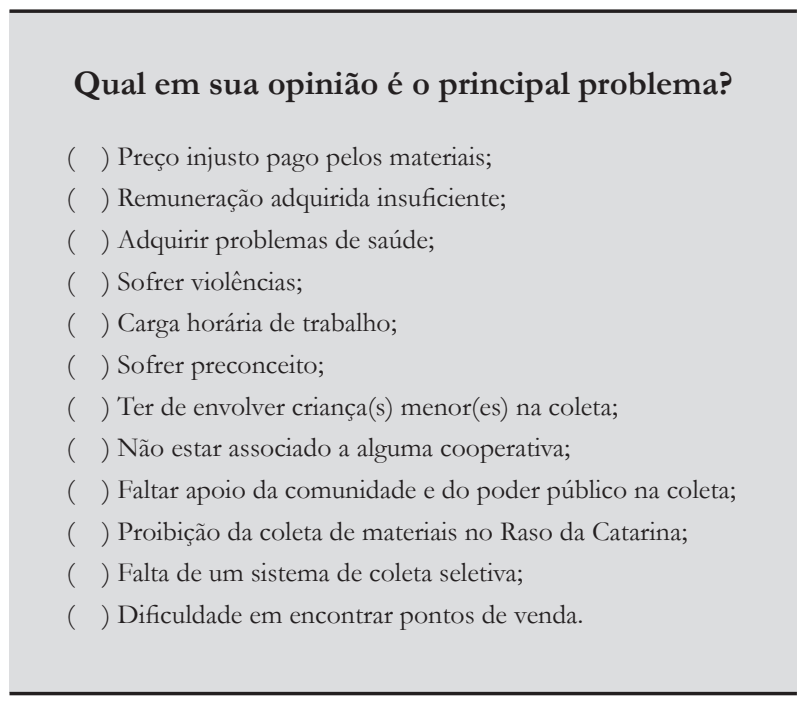

Figura 2 - Questionário sobre os principais problemas encontrados pelos catadores de lixo

A interpretação dos dados foi realizada tendo como base a predominância de catadores de lixo em cada um dos patamares, para cada parâmetro investigado, estabelecendo assim um quadro sobre a situação socioeconômica e sobre as principais dificuldades da população de catadores de materiais recicláveis das já mencionadas cidades.

\section{Resultados e discussão}

A partir dos resultados obtidos nas entrevistas, foram elaboradas tabelas que abordam separadamente cada um dos aspectos socioeconômicos do questionário. Para a caracterização socioeconômica, os primeiros pontos detectados foram: que a maioria dos entrevistados era do sexo feminino (Tabela 1) e estavam na faixa etária acima de 40 anos de idade (Tabela 2).

Tabela 1 - Divisão dos catadores de lixo por gênero

\begin{tabular}{lcc}
\hline Sexo & $\mathbf{n .}$ & $\mathbf{\%}$ \\
\hline Feminino & 19 & 59,4 \\
Masculino & 13 & 40,6 \\
\hline Total & $\mathbf{3 2}$ & $\mathbf{1 0 0}$ \\
\hline
\end{tabular}

Tabela 2 - Faixa etária dos catadores de lixo

\begin{tabular}{lrr}
\hline Faixa etária & n. & \% \\
\hline Até 20 anos & 1 & 3,1 \\
De 20 a 40 anos & 8 & 25,0 \\
Acima de 40 anos & 23 & 71,9 \\
\hline Total & $\mathbf{3 2}$ & $\mathbf{1 0 0}$ \\
\hline
\end{tabular}

Quanto à escolaridade dos catadores de lixo, verificou-se que 53,1\% não sabem ler e nem escrever, enquanto que $25 \%$ sabem ler e escrever, 9,4\% possuem o ensino fundamental incompleto, 3,1\% concluíram o ensino fundamental, 9,4\% têm o ensino médio incompleto e nenhum dos entrevistados concluiu o ensino médio (Tabela 3). 
Tabela 3 - Escolaridade dos catadores de lixo

\begin{tabular}{lrc}
\hline Escolaridade & $\mathbf{n .}$ & \% \\
\hline Não foi alfabetizado & 17 & 53,1 \\
Apenas alfabetizado & 8 & 25,0 \\
Ensino fundamental incompleto & 3 & 9,4 \\
Ensino fundamental completo & 1 & 3,1 \\
Ensino médio incompleto & 3 & 9,4 \\
Ensino médio completo & 0 & - \\
\hline Total & 32 & $\mathbf{1 0 0}$ \\
\hline
\end{tabular}

A Tabela 4 demonstra que o tempo que os catadores exercem a atividade de coleta é variado, com $18,7 \%$ na atividade a menos de um ano, sendo que a maioria declarou trabalhar com "catação" de dois a três anos $(59,4 \%)$, seguida por três a seis anos $(21,9)$. Nenhum dos entrevistados trabalha com coleta há mais de seis anos.

Tabela 4 - Tempo de exercício da atividade de coleta

\begin{tabular}{lrc}
\hline Tempo & n. & \% \\
\hline Menos de um ano & 6 & 18,7 \\
De dois a três anos & 19 & 59,4 \\
Entre três e seis anos & 7 & 21,9 \\
Mais de seis anos & 0 & - \\
\hline Total & $\mathbf{3 2}$ & $\mathbf{1 0 0}$ \\
\hline
\end{tabular}

No que diz respeito aos materiais recolhidos, a maioria recolhe o papel e a garrafa PET, por serem os materiais mais abundantes (Gráfico 1). Como pode ser observado na Tabela 5, a maioria desses materiais, segundo os catadores, é coletado em residências.

Quando perguntados qual a frequência com que vendiam o material, 59,4\% optaram por outra opção de venda, $34,4 \%$ vendem semanalmente, enquanto apenas $6,3 \%$ costumam vender os materiais coletados diariamente (Tabela 6). De acordo com a Tabela 7 , pode ser observada uma grande variedade no peso dos materiais recolhidos mensalmente pelos catadores: 40,6\% recolhe até $300 \mathrm{~kg}, 34,4 \%$ dos entrevistados recolhe de 100 a $200 \mathrm{~kg}, 12,5 \%$ coleta até $50 \mathrm{~kg}, 9,4 \%$ recolhe de 50 a $100 \mathrm{~kg}$, e 3,1\% conseguem juntar mais de $300 \mathrm{~kg}$ por mês.

$\mathrm{Na}$ Tabela 8 estão representadas as variações de valores recebidos pelos catadores, em que nenhum dos catadores entrevistados recebem menos de $\mathrm{R} \$ 50 / \mathrm{mês}, 12,5 \%$ disseram receber pelo material vendido de $\mathrm{R} \$ 51$ até R \$ 100, 50\% dos catadores entrevistados ganham até R \$200/mês, 28,1\% declaram receber até R \$ 300/mês, enquanto apenas 9,4\% conseguem receber mais de R \$ 300 pelo material vendido. É possível observar na Tabela 9 que geralmente $(53,1 \%$ dos catadores entrevistados) mais de seis pessoas vivem de renda obtida pelos catadores de lixo, recebendo como complemento auxílios do governo, como a Bolsa Família $(53,1 \%)$ e a Bolsa Escola (40,6\%) (Tabela 10). 


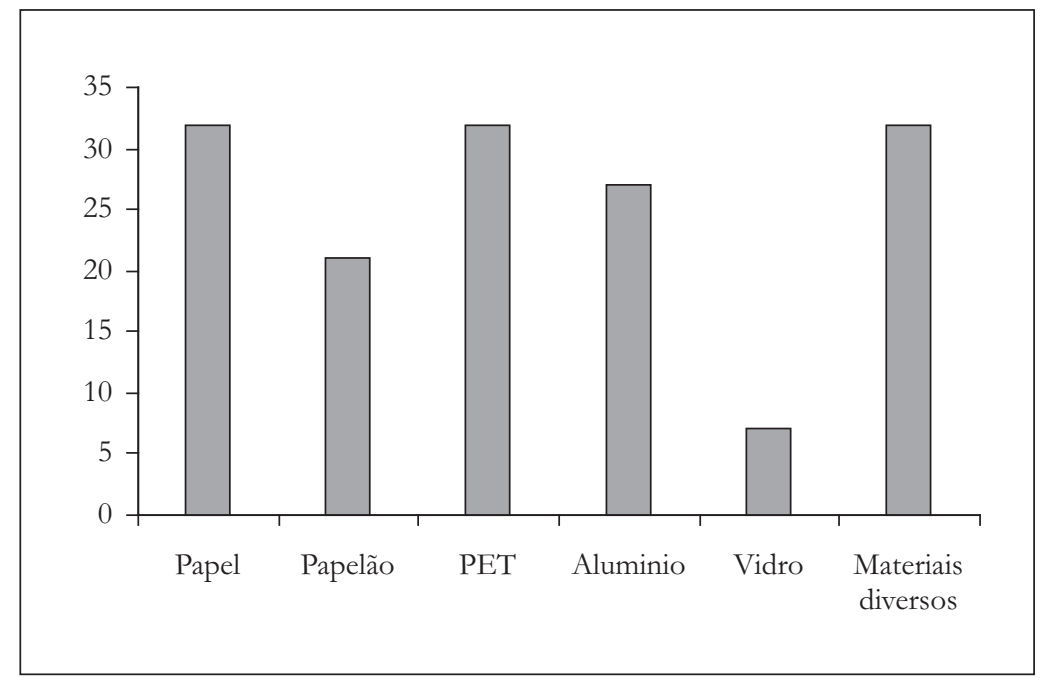

Gráfico 1 - Tipos de materiais mais vendidos pelos catadores de lixo

Tabela 5 - Locais de coleta materiais dos catadores de lixo

\begin{tabular}{lcc}
\hline Locais & $\mathbf{n .}$ & \% \\
\hline Supermercados* & 6 & 18,7 \\
Hospitais* & 9 & 28,1 \\
Escolas* & 7 & 21,9 \\
Residências* & 10 & 31,3 \\
\hline Total & $\mathbf{3 2}$ & $\mathbf{1 0 0}$ \\
\hline
\end{tabular}

* As respostas foram unânimes no sentido de que a coleta é realizada em vários locais; pedimos então que citassem o mais representativo quantitativamente

Tabela 6 - Frequência da venda do material pelos catadores de lixo

\begin{tabular}{lcc}
\hline Frequência & n. & \% \\
\hline Diariamente & 2 & 6,3 \\
Semanalmente & 11 & 34,4 \\
Mensalmente & 0 & - \\
Outra opção* & 19 & 59,4 \\
\hline Total & $\mathbf{3 2}$ & $\mathbf{1 0 0}$ \\
\hline
\end{tabular}

* Dentre os 19 entrevistados que optaram por "outra opção", 17 responderam que vendem quinzenalmente 
Tabela 7 - Peso do material vendido por mês pelos catadores de lixo

\begin{tabular}{lcc}
\hline Peso & n. & \% \\
\hline Até $50 \mathrm{~kg}$ & 4 & 12,5 \\
50 a $100 \mathrm{~kg}$ & 3 & 9,4 \\
100 a $200 \mathrm{~kg}$ & 11 & 34,4 \\
200 a $300 \mathrm{~kg}$ & 13 & 40,6 \\
Mais de $300 \mathrm{~kg}$ & 1 & 3,1 \\
\hline Total & $\mathbf{3 2}$ & $\mathbf{1 0 0}$ \\
\hline
\end{tabular}

Tabela 8 - Valor recebido pelo material vendido por mês pelos catadores de lixo

\begin{tabular}{lcc}
\hline Valor & n. & \% \\
\hline $\mathrm{R} \$ 10$ a $\mathrm{R} \$ 50$ & 0 & - \\
$\mathrm{R} \$ 51$ a $\mathrm{R} \$ 100$ & 4 & 12,5 \\
$\mathrm{R} \$ 101$ a $\mathrm{R} \$ 200$ & 16 & 50,0 \\
$\mathrm{R} \$ 201$ a $\mathrm{R} \$ 300$ & 9 & 28,1 \\
Superior a $\mathrm{R} \$ 300$ & 3 & 9,4 \\
\hline Total & $\mathbf{3 2}$ & $\mathbf{1 0 0}$ \\
\hline
\end{tabular}

Tabela 9 - Número de pessoas que vivem da renda mensal dos catadores de lixo

\begin{tabular}{lcc}
\hline Número de pessoas & $\mathbf{n}$. & $\%$ \\
\hline 1 pessoa & 0 & - \\
2 pessoas & 1 & 3,1 \\
3 pessoas & 0 & - \\
4 pessoas & 6 & 18,7 \\
5 pessoas & 6 & 18,7 \\
6 pessoas & 2 & 6,3 \\
Mais de 6 pessoas & 17 & 53,1 \\
\hline Total & 32 & $\mathbf{1 0 0}$ \\
\hline
\end{tabular}


Tabela 10 - Benefícios sociais do governo, recebidos pelos catadores de lixo

\begin{tabular}{lcc}
\hline Benefícios & n. & \% \\
\hline Não recebe & 0 & - \\
Bolsa Escola & 13 & 40,6 \\
Bolsa Família & 17 & 53,1 \\
Outro beneficio & 2 & 6,3 \\
Não respondeu & 0 & - \\
\hline Total & $\mathbf{3 2}$ & $\mathbf{1 0 0}$ \\
\hline
\end{tabular}

Os catadores relataram na Tabela 11 que na maioria dos casos (75\%) o valor obtido pela venda dos materiais é insuficiente para o sustento de suas famílias. Poucos (25\%) acreditam que ganham o suficiente.

Tabela 11 - Suficiência da remuneração adquirida com a venda dos materiais

\begin{tabular}{lcc}
\hline Suficiência & n. & $\%$ \\
\hline É mais que o necessário & 0 & - \\
É o suficiente & 8 & 25 \\
É pouco & 24 & 75 \\
\hline Total & 32 & $\mathbf{1 0 0}$ \\
\hline
\end{tabular}

Quando perguntados a respeito dos problemas de saúde ocorridos no exercício da atividade, 56,3\% dos catadores afirmaram ter problemas. A maioria diz apresentar problemas de dores na coluna e doenças de pele, adquiridos por conta do esforço repetitivo, como agachamento na coleta e exposição excessiva ao sol (Tabela 12).

Tabela 12 - Catadores que adquiriram problemas de saúde decorrente dessa atividade

\begin{tabular}{lcc}
\hline Problemas de saúde & n. & $\%$ \\
\hline Sim* & 18 & 56,3 \\
Agravei problemas já existentes & 11 & 34,3 \\
Não adquiri nenhum problema & 3 & 9,4 \\
\hline Total & 32 & $\mathbf{1 0 0}$ \\
\hline
\end{tabular}

* Deste grupo, a maioria relatou problemas de coluna resultantes dos movimentos repetitivos e problemas de peles pela prolongada exposição ao sol. 
Quando perguntados se haviam sofrido algum tipo de preconceito, 84,4\% afirmaram que sim (Tabela 13). A maioria dos catadores afirmou ter sofrido algum tipo de violência verbal (81,3\%) ou física $(12,5 \%)$ no exercício da atividade (Tabela 14$)$.

Tabela 13 - Violência sofrida por catadores de lixo durante o exercício da profissão

\begin{tabular}{lrc}
\hline Violência sofrida & n. & \% \\
\hline Sim, violência verbal & 26 & 81,3 \\
Sim, violência física & 3 & 12,5 \\
Nunca sofri violência & 2 & 6,3 \\
\hline Total & $\mathbf{3 2}$ & $\mathbf{1 0 0}$ \\
\hline
\end{tabular}

Tabela 14 - Preconceitos sofridos enquanto coletava ou por simplesmente ser conhecido como catador

\begin{tabular}{lrc}
\hline Preconceitos sofridos & n. & $\%$ \\
\hline Sim, algumas vezes & 5 & 15,6 \\
Sim, com frequência* & 27 & 84,4 \\
Nunca sofri preconceito & 0 & - \\
\hline Total & 32 & $\mathbf{1 0 0}$ \\
\hline
\end{tabular}

* Todos afirmaram sofrer preconceito, tanto durante as coletas quanto em momentos em que não estavam coletando, pelo simples fato de exercer a profissão

Em relação à jornada de trabalho, a maioria trabalha 8 horas/dia, como se verifica na Tabela 15. Quando perguntados se crianças (filhos ou outros) ajudam na coleta do material, 90,6\% responderam que não. Muitos afirmaram manter as crianças na escola para permanecer com o auxilio do governo. Apenas $9,4 \%$ confirmam que contam com o auxilio de crianças, mas que elas não deixaram de frequentar a escola (Tabela 16).

Tabela 15 - Carga horária diária dos catadores de lixo

\begin{tabular}{lcc}
\hline Carga horária & n. & $\%$ \\
\hline 6 a 8 horas/dia & 29 & 90,6 \\
8 a 10 horas/dia & 3 & 9,4 \\
Mais de 10 horas/dia & 0 & - \\
\hline Total & $\mathbf{3 2}$ & $\mathbf{1 0 0}$ \\
\hline
\end{tabular}

Rev. Acad., Ciênc. Agrár. Ambient., Curitiba, v. 8, n. 2, p. 235-248, abr./jun. 2010 
Tabela 16 - Envolvimento de crianças (filhos ou não) na coleta

\begin{tabular}{lcc}
\hline Envolvimento de crianças & $\mathbf{n .}$ & $\mathbf{0}$ \\
\hline Sim, mas as crianças continuam indo à escola* & 3 & 9,4 \\
Sim, por isso as crianças não vão à escola & 0 & - \\
Não tenho crianças trabalhando comigo* & 29 & 90,6 \\
\hline Total & $\mathbf{3 2}$ & $\mathbf{1 0 0}$ \\
\hline * Em ambos os casos, a maioria afirmou manter as crianças na escola para não perder o \\
benefício social do governo
\end{tabular}

$\mathrm{Na}$ Tabela 17 observa-se que 53,1\% dos entrevistados afirmam que não fazem parte de nenhuma cooperativa; neste caso, os catadores alegam que o pagamento da taxa mensal, cobrado pelas cooperativas, muitas vezes é o fator limitante para não se associarem; 37,5\% já participaram, no entanto não obtiveram benefícios; e, por fim, 9,4\% participam e crêem que o trabalho torna-se mais lucrativo.

Tabela 17 - Catadores participantes de cooperativa

\begin{tabular}{lrc}
\hline Participação em cooperativa & n. & $\mathbf{\%}$ \\
\hline Sim, o trabalho fica mais lucrativo assim & 3 & 9,4 \\
Sim, mas não obtive benefícios & 12 & 37,5 \\
Não sou associado* & 17 & 53,1 \\
\hline Total & $\mathbf{3 2}$ & $\mathbf{1 0 0}$ \\
\hline
\end{tabular}

* Os não associados abordaram que o pagamento da taxa mensal muitas vezes é o fator limitante para não se associarem

Com relação ao apoio da comunidade e do poder público oferecido à classe de catadores, 56,3\% afirmam ter o apoio da comunidade onde coletam e 43,7\% dos catadores entrevistados dizem faltar apoio (Tabela 18). Dos catadores abordados, $96,9 \%$ entendem ser importante o apoio comunitário e governamental, por meio da implantação de um sistema de coleta seletiva (Tabela 19).

O "Raso da Catarina" é um lixão, localizado no bairro José e Maria, em Petrolina, no qual os catadores de lixo da referida cidade costumavam realizar suas coletas, até que a prefeitura municipal resolveu transformar o lixão em aterro controlado, proibindo os catadores de fazer coletas. Quanto a essa questão, $46,9 \%$ dos catadores demonstraram ter tido uma diminuição de material coletado, enquanto todos os outros $(53,1 \%)$ não realizavam coletas no "Raso da Catarina" e, por isso, não tiveram prejuízos (Tabela 20). Isso mostra que todos os entrevistados que coletavam no referido local tiveram problemas em realizar a coleta depois da proibição.

Os catadores $(84,4 \%)$ disseram encontrar facilmente pontos de vendas (Tabela 21), porém a maioria (56,3\%) não crê que o preço pago seja justo (Tabela 22). 
Tabela 18 - Apoio da comunidade e do poder público na coleta seletiva do lixo

\begin{tabular}{lcc}
\hline Apoio da comunidade & n. & $\mathbf{\%}$ \\
\hline Falta apoio, mas não faz tanta diferença & 0 & - \\
Falta apoio, ele seria muito importante & 14 & 43,7 \\
Tenho apoio na comunidade onde coleto & 18 & 56,3 \\
\hline Total & 32 & $\mathbf{1 0 0}$ \\
\hline
\end{tabular}

Tabela 19 - Necessidade de implantar um sistema de coleta seletiva

\begin{tabular}{lcc}
\hline Implantação de coleta seletiva & $\mathbf{n .}$ & $\mathbf{\%}$ \\
\hline Sim & 31 & 96,9 \\
Não & 1 & 3,1 \\
\hline Total & 32 & $\mathbf{1 0 0}$ \\
\hline
\end{tabular}

Tabela 20 - Consequências da proibição de coletar materiais no lixão "Raso da Catarina"

\begin{tabular}{lccc}
\hline Proibição da coleta de materiais no Raso da Catarina & n. & \% \\
\hline Tive uma redução na coleta após a proibição* & 15 & 46,9 \\
Não tive dificuldade de trabalhar após a proibição & 0 & - \\
Não coletava material no Raso da Catarina & 17 & 53,1 \\
\hline Total & $\mathbf{3 2}$ & $\mathbf{1 0 0}$ \\
\hline
\end{tabular}

* Todos os catadores relataram o fato de não terem recebido o treinamento e o auxílio prometido pela Prefeitura Municipal de Petrolina, quando houve a proibição de coletar no "Raso da Catarina" (lixão da cidade de Petrolina)

Tabela 21 - Necessidade de implantar um sistema de coleta seletiva

\begin{tabular}{lrc}
\hline Implantação de coleta seletiva & $\mathbf{n .}$ & $\mathbf{\%}$ \\
\hline Sim & 31 & 96,9 \\
Não & 1 & 3,1 \\
\hline Total & 32 & $\mathbf{1 0 0}$ \\
\hline
\end{tabular}

Rev. Acad., Ciênc. Agrár. Ambient., Curitiba, v. 8, n. 2, p. 235-248, abr./jun. 2010 
Tabela 22 - Opinião dos catadores quanto ao preço pago pelos materiais

\begin{tabular}{lcc}
\hline Preço justo & n. & \% \\
\hline Sim & 14 & 43,7 \\
Não & 18 & 56,3 \\
\hline Total & 32 & $\mathbf{1 0 0}$ \\
\hline
\end{tabular}

Dentro de todas as problemáticas abordadas, quando perguntados qual a principal dificuldade encontrada na atividade de lixo, os pontos mais citados foram: a insuficiência da remuneração recebida, os problemas de saúde adquiridos durante as coletas e as violências sofridas, como pode ser visto na Tabela 23.

Tabela 23 - Principais problemas encontrados pelos catadores de lixo

\begin{tabular}{lcc}
\hline Principais problemas & n. & $\%$ \\
\hline Remuneração adquirida insuficiente & 9 & 28,1 \\
Adquirir problemas de saúde & 4 & 12,5 \\
Sofrer violências & 6 & 18,7 \\
Carga horária de trabalho & 0 & - \\
Sofrer preconceito & 4 & 12,5 \\
Ter que envolver criança(s) menor(es) na coleta & 0 & - \\
Não estar associado à alguma cooperativa & 0 & - \\
Faltar apoio da comunidade e do poder público na coleta & 0 & - \\
Proibição da coleta de materiais no "Raso da Catarina” & 6 & 18,7 \\
Falta de um sistema de coleta seletiva & 2 & 6,3 \\
Dificuldade em encontrar pontos de venda & 0 & - \\
Preço injusto pago pelos materiais & 1 & 3,1 \\
\hline Total & $\mathbf{3 2}$ & $\mathbf{1 0 0}$ \\
\hline
\end{tabular}

\section{Conclusão}

A caracterização socioeconômica dos catadores mostra que a maioria é do sexo feminino, possui mais de 40 anos, alfabeta e em geral exerce a atividade de coleta de lixo há dois ou três anos. Coletam em média de 200 a $300 \mathrm{~kg} /$ catador/mês, obtendo cerca de R $\$ 200$, e em grande parte dos casos essa é a principal renda utilizada para sustentar as famílias (que possuem em média seis pessoas), contando apenas com o auxílio de benefícios sociais do governo. 
Das dificuldades encontradas pelos catadores, destacam-se a insuficiência da remuneração para o sustento da família, a aquisição de problemas de saúde decorrentes da atividade e a exposição à violência e/ou ao preconceito; assim, conclui-se que os catadores de lixo de Petrolina e Juazeiro enfrentam inúmeros problemas.

\section{Referências}

ACURIO, G. et al. Diagnóstico de la situación del manejo de los residuos sólidos municipales en América Latina y el Caribe. Washington, DC: Banco Interamericano de Desarrollo/Organización Panamericana de La Salud, 1997.

CALDERONI, S. Os bilhões perdidos no lixo. São Paulo: Humanitas, 1996.

CAPUCHA, L. M. A exclusão social e acesso ao emprego: paralelas que podem convergir. Sociedade \& Trabalho, n. 3, p. 61-69, 1998.

INSTITUTO BRASILEIRO DE GEOGRAFIA E ESTATÍSTICA - IBGE. Pesquisa Nacional por Amostras de Domicílios de 2007: microdados. Disponível em: <http://www.ibge.gov.br>. Acesso em: 9 ago. 2009.

LARREA, C.; BARRETO, M. Acompanhamento das mudanças das percepções da população resultantes das ações do programa Bahia Azul. Relatório técnico de pesquisa. Salvador: Secretaria de Recursos Hídricos Saneamento e Habitação/ Instituto de Saúde Coletiva, Universidade Federal da Bahia, 1999.

MINISTÉRIO DO MEIO AMBIENTE - MMA. Agenda 21 Brasileira: bases para a discussão. Brasília: MMA, 1999. ORGANIZAÇÃO DAS NAÇÕES UNIDAS - ONU. Environmentally sound management of solid waste and sewage-related issue in 1999. Disponível em: <http://www.un.org>. Acesso em: 26 ago. 2009.

ORGANIZACIÓN PANAMERICANA DE LA SALUD - OPS. Nuestro Planeta, Nuestra Salud: informe de la Comisión de Salud y Medio Ambiente de la OMS. Washington, DC: OPS, 1993. Publicación Científica 505.

Recebido: 25/01/2010

Received: $01 / 25 / 2010$

Aprovado: $26 / 03 / 2010$

Approved: 03/26/2010

Rev. Acad., Ciênc. Agrár. Ambient., Curitiba, v. 8, n. 2, p. 235-248, abr./jun. 2010 